\title{
Electrolyzer Switching Strategy for Hydrogen Generation from Variable Speed Wind Generator
}

\author{
S. M. Muyeen", R. Takahashi, and J. Tamura \\ "The Petroleum Institute, Department of Electrical Engineering, P.O. Box 2533, Abu Dhabi, \\ U.A.E.
}

\section{Kitami Institute of Technology, 165 Koen-Cho, Kitami, Hokkaido, 090-8507, Japan}

\begin{abstract}
This paper presents a new switching strategy for electrolyzer used in hydrogen generation which is connected to the terminal of a wind farm. The output of wind generator, in general, fluctuates greatly due to the random wind speed variations, which has a serious influence on the power system operation. In this study, the wind farm is composed of variable speed wind turbines (VSWT) driving Permanent Magnet Synchronous Generators (PMSG). The Hydrogen Generator $(\mathrm{HG})$ is composed of rectifier and 10 electrolyzer units where each unit is controlled by the chopper circuit. To smoothen the wind farm line power, at first, a reference for the line power is generated from the difference of exponential moving average of wind farm output and its standard deviation. Then the switching strategy is developed in such a way that the proposed cooperative system can smoothen the wind farm line power fluctuation as well as generating hydrogen gas absorbing the fluctuating portion of wind farm output that lies above the reference line power. This novel switching strategy helps each electrolyzer unit working in full load and shift operation conditions and hence increases its lifespan and efficiency. The performance of the proposed system is investigated by simulation analyses, in which simulations are performed by using PSCAD/EMTDC.
\end{abstract}

Index Terms-dc-chopper, electrolyzer, maximum power point tracking, variable speed wind turbine (VSWT), voltage source converter (VSC), wind power smoothening. 


\section{Introduction}

Hydrogen has received much attention nowadays from the viewpoint of exhaustion problem of fossil fuel as well as to prevent global warming. Besides the large scale industrial uses, one of the recent trends is to use hydrogen in energy station for fueling the vehicles. Hydrogen is the most abundant element in the universe, making up $75 \%$ of the mass of all visible matter in stars and galaxies [1]. However, all the hydrogen is in combination with other elements such as natural gas (where, methane, $\mathrm{CH}_{4}$, is the main component) and water $\left(\mathrm{H}_{2} \mathrm{O}\right)$. Small-scale distributed hydrogen production from natural gas is most economical. Advanced natural gas to hydrogen refueling stations are being field evaluated. Statistic says that approximately $90 \%$ of the produced hydrogen is obtained from natural resources such as natural gas, coal, and oil through the process called reformation.

On the other hand, the electrolyzer technology is available today, but using electricity produced from fossil fuels to make hydrogen creates significant greenhouse gases. However, electrolyzers open the possibility of using electricity made from renewable and nuclear sources to produce carbon-free hydrogen. Among the renewable energy sources wind energy is playing the major role to fulfill the energy demand of this modern world. In 2007, 20,000 MW of wind power was installed all over the world, bringing world-wide installed capacity to 94,112 MW [2]. Therefore, in this study, hydrogen production from wind energy, rather than other renewable sources of energy, is focused using electrolysis process. The common issue of output power fluctuation of wind farm is solved by developing the advanced switching strategy for hydrogen generator.

Variable speed wind turbine generator system (WTGS) is considered in this study, taking account its huge market share at the present [3]. Though doubly fed induction generator (DFIG) is widely used as variable speed wind generator [4-8], permanent magnet synchronous generator (PMSG) is considered for this study due to some inherent advantages of it. Permanent magnet machines are characterized as having large air gaps, which reduce flux linkage even in machines with multi magnetic poles [9-10]. As a result, low rotational speed generators can be manufactured with relatively small sizes with respect to its power rating. Therefore, gearbox can be omitted when PMSG is used as variable speed wind generator. In [11-19], various types of frequency converter topologies including the control strategy are presented for the operation of VSWT-PMSG. In this paper, a simple type of frequency converter composed of rectifier, boost converter, and grid-side DC/AC inverter is considered, where interpolated firing pulses are used as the switching signals for the insulated gate bipolar transistors (IGBT) of both converter and inverter. The detailed control schemes of both converter/inverter are presented.

Though hydrogen generation using wind energy is becoming popular these days, there are not so many reports available 
in literature on this topic. In [20], the hydrogen generation topologies suitable for variable speed wind generator were discussed, where electrolyzer is connected to the dc-link of the frequency converter. Nice study is presented in [21], where hydrogen is generated from standalone VSWT-PMSG. Hydrogen production from hybrid system is presented in [22]. Different types of hydrogen storage methodologies are discussed in [23]. Details of hydrogen production using fixed speed wind generators are presented in [24]. In general, hydrogen generator can be considered to be connected at DC link of each unit or terminal of wind farm. It should be noted that connecting the hydrogen generator in the wind farm terminal using an additional three-phase rectifier may result in the drawbacks of poor efficiency and extra harmonic current. Therefore, best way might be to connect the hydrogen generator in the DC link of wind generator which operates in variable speed. In that case, a coordinated control scheme among different variable speed wind generator units is essential to smooth the wind farm line power as desired by transmission system operators (TSOs) and cost of the control unit for each hydrogen generator should be taken into consideration as well.

In this paper, minimization of wind farm line power fluctuation is proposed without considering any additional energy storage system using a hydrogen generator where multiple electrolyzer units are used instead of a large unit considering the issues of lifespan and efficiency. The switching scheme of multiple electrolyzer units are the main objective of this study. Therefore, hydrogen generator consist of multiple electrolyzer units is considered to be connected to the wind farm terminal in a simple way using a three phase rectifier scheme for the sake of avoiding intricacy of the coordinated control scheme among all wind generators in a wind farm and hence overall efficiency is not taken into consideration, in this study. The same switching scheme definitely can be adopted to the system where the hydrogen generator is connected to the DC-link of the frequency converter, just considering the coordinated control scheme among different units.

In this study, variable load operation of electrolyzer may have some adverse effect on its lifespan and efficiency. Therefore, in this study, 10 small electrolyzer units are considered instead of a large one, in which each unit operates only at rated load. Moreover, operation shift of the electrolyzer units are also considered to distribute the loading equally among all units. To smoothen the wind farm line power, it is very important to generate a line power reference. In our earlier work, we used energy capacitor system to smoothen the wind farm output power [25]. However, in the present study, as no energy storage device is considered, the reference is chosen in such a way that most of the fluctuated output will be absorbed by the hydrogen generator and as a result smoothened line power can be obtained. Considering this strategy, the line power reference is generated from the difference of exponential moving average of wind farm output and its standard 
deviation. Then a novel algorithm is developed for the switching of multi-electrolyzer units keeping in mind the following points.

a. Number of active electrolyzer units depends on how much fluctuating power needs to be absorbed.

b. The electrolyzer will be switched off according to the FIFO (First-In-First-Out) algorithm, which is implemented based on electrolyzer loading concept. Therefore, the operation time of each electrolyzer can be averaged.

c. During electrolyzer switch on, operation shifting is maintained.

d. Excessive electrolyzer switching should be avoided.

e. Soft start of electrolyzer switching is adopted in the chopper duty cycle control.

Extensive simulation analyses have been performed by using PSCAD/EMTDC, which shows the validity of the proposed control system. It is needed to mention here that the incorporation of hydrogen electrolyzer with a partial capacity of a wind farm can even respond to grid operator requests to ramp up the power instantly by switching off the electrolyzer units. Finally, it is concluded that the proposed cooperative control is very effective for smoothing the wind farm line power without integrating any costly energy storage system.

\section{II.Wind Turbine Modeling}

The mathematical relation for the mechanical power extraction from the wind can be expressed as follows [26]:

$$
\mathrm{P}_{\mathrm{w}}=0.5 \rho \pi \mathrm{R}^{2} \mathrm{~V}_{\mathrm{w}}^{3} \mathrm{C}_{\mathrm{P}}(\lambda, \beta)
$$

where $P_{w}$ is the extracted power from the wind, $\rho$ is the air density $\left[\mathrm{kg} / \mathrm{m}^{3}\right], R$ is the blade radius $[\mathrm{m}], V_{w}$ is the wind speed $[\mathrm{m} / \mathrm{s}]$ and $\mathrm{C}_{\mathrm{p}}$ is the power coefficient which is a function of both tip speed ratio, $\lambda$, and blade pitch angle, $\beta$ [deg].

In variable speed WTGS, generated active power depends on the power coefficient, $C_{p}$, which is related to the proportion of power extracted from the wind. For each instantaneous wind speed, there is a specific turbine rotational speed, which corresponds to the maximum active power extraction from the wind. In this way, the maximum power point tracking (MPPT) in variable speed WTGS increases the energy generation at all types of wind conditions. The wind turbine characteristic with maximum power point trajectory used in this study is depicted in Fig. 1 [26-27].

Since the measurement of the precise wind speed is difficult, in this study, the maximum power, $\mathrm{P}_{\max }$, (which is used as the reference power of the frequency converter) is calculated without the measurement of wind speed as shown below. 
$\mathrm{P}_{\max }=0.5 \rho \pi \mathrm{R}^{2}\left(\frac{\omega_{\mathrm{r}} \mathrm{R}}{\lambda_{\text {opt }}}\right)^{3} \mathrm{C}_{\mathrm{p}_{-} \mathrm{opt}}$

where, $\omega_{\mathrm{r}}$ denotes the rotor speed of wind turbine, $\lambda_{\text {opt }}$ and $\mathrm{C}_{\mathrm{p}_{\mathrm{o}} \text { opt }}$ are optimum values of tip speed ratio and power coefficient respectively.

If the rotational speed exceeds the rated speed of wind turbine, then pitch controller is activated and thus reference power is controlled. In this study, the pitch controller presented in [17] is used in the simulations.

\section{Modeling of Frequency Converter}

Two types of frequency converter schemes are available that suit with direct drive variable speed wind turbine driven permanent magnet synchronous generator. One is the fully controlled frequency converter consists of generator side $\mathrm{AC} / \mathrm{DC}$ converter, DC-link capacitor, and grid side DC/AC inverter as shown in Fig. 2. Each of converter/inverter is a standard 3-phase two-level unit, composed of six IGBTs and anti-parallel diodes. In this scheme, as the converter is directly connected to the PMSG, its q-axis current is proportional to the active power. The active power reference can be determined in such a way to provide the maximum power to the grid as explained in Sect. II. On the other hand, the d-axis stator current is proportional to the reactive power. The reactive power reference is set to zero to perform unit power factor operation. In the second scheme, the frequency converter is composed of rectifier, boost converter, and grid side DC/AC inverter. The schematic diagram of this scheme used in VSWT-PMSG is shown in Fig. 3, where MPPT control can be handled by the boost converter. In both schemes, the grid inverter helps to maintain constant DC-link voltage and AC grid voltage.

For simplicity, the second scheme of the frequency converter is considered in this study. The PMSG model available in the package software PSCAD/EMTDC [28] is used. The interpolated firing pulse circuit is considered in the simulation, which enables an exact switching between time steps based on a comparison between the sinusoidal reference and the highfrequency carrier signal [29]. The rated DC link voltage is $2.3 \mathrm{kV}$.

\section{Modeling of Hydrogen Generator}

The Faraday's law for electrolysis can be expressed briefly with the following equation. 
$\eta=\frac{\mathrm{It}}{\mathrm{zF}}$

where $\mathrm{I}$ is the current in Ampere, $\mathrm{t}$ is the time in sec, $\mathrm{z}$ is the valence number of ions of the substance (electrons transferred per ion), $F$ is the Faraday Constant, and $\eta$ is the amount of substance ("number of moles") produced.

According to the Faraday's Law of Electrolysis, it is possible to generate hydrogen gas by using electrolyzer (ELL). From eq.(3), it is clear that the amount of produced hydrogen depends on only the electrolyzer current. Therefore, the hydrogen generator can be simulated with the electrolyzer and the power electronic devices that will provide constant current to the electrolyzer [24].

In this paper hydrogen generator composed of rectifier, dc chopper, and electrolyzer is considered. For smoothening the wind farm line output power, it is not a good method to use only one electrolyzer of a large capacity because operation in partial loading condition is needed in this case. It is needed to mention here that electrical load on electrolyzer should be maintained constant because varying load operation of electrolyzer might not be a good choice from practical viewpoints. The adverse effect of fluctuating input power to the electrolyzer on its lifespan is reported in [31]. The degradation of electrolyzer performance due to lower efficiency is clearly stated in [30-32]. Moreover, lower temperature even decreases the hydrogen generation rate from electrolyzer, which is also stated in [32]. This important constrain pave the way to combine multiple small capacity electrolyzer units (10 units are considered in this study) instead of one large unit as depicted in Fig. 4. Simple rectifier circuit is used to convert the ac voltage to dc voltage as shown in Fig. 4. To simulate the electrolyzer, it is necessary to know the electrolyzer characteristic precisely. The electrolyzer characteristic used in this study is available in [24]. The parameters of single electrolyzer unit is shown in Table I. The details of the electrolyzer switching scheme are demonstrated in the following section.

\section{Smoothing Operation using Proposed Switching Scheme}

The power generation from conventional energy sources can be controlled straightforwardly. Therefore, it is better to extract maximum power from the renewable energy sources like solar or wind without degrading the power quality so much and to control the conventional energy sources to fulfill the scheduled load demand. Each VSWT-PMSG of the wind farm generates the maximum power as the maximum power point tracking is achieved in each generator by the control of generator side boost converter. As a result, the total power obtained from the entire wind farm reflects the maximum power extraction by individual unit. In this study, multiple small size electrolyzer units are used to absorb the fluctuation of the wind farm output power and thus smoothed power can be delivered to the power grid from the wind farm. The number of 
electrolyzer units those should participate in the smoothing operation at any particular instant depends on the amount of fluctuating quantity of wind farm output power to be absorbed. In the following section the wind power smoothing operation is explained.

\section{A) Determination of Wind Farm Line Power Reference}

In the proposed scheme, it is required to determine the reference line power, $\mathrm{P}_{\mathrm{L}_{\mathrm{B}} \mathrm{REF}}$, to smoothen the wind farm output fluctuation, so that when wind farm output exceeds the reference power will be absorbed by the hydrogen generator. Therefore, special attention is required to set this reference power because too many fluctuation above and below this reference would deteriorate the overall smoothing performance. The reference generation scheme is explained as follows.

At first, exponential moving average (EMA), $\mathrm{P}_{\mathrm{WF} \_ \text {EMA }}$, of the wind farm output, $\mathrm{P}_{\mathrm{WF}}$, is calculated from the following equation.

$\operatorname{EMA}(\mathrm{C})=[(\mathrm{C}-\mathrm{P}) \times \mathrm{K}]+\mathrm{P}$

Where,

$\mathrm{C}=$ The current value

$\mathrm{P}=$ The previous period's EMA

$\mathrm{K}=$ Weighting factor

For a period-based EMA, "K" is equal to $2 /(1+\mathrm{N})$, where $\mathrm{N}$ is the specified number of periods. For example, a 10 period EMA's "weighting factor" is calculated like this: $2 /(1+10)=0.1818$. Number of period can be chosen randomly and in this study 60 period $(180 \mathrm{sec})$ EMA value is used in the simulation. Detailed of the EMA can be found in [24].

Then $\mathrm{P}_{\mathrm{L}_{-} \mathrm{REF}}$ is determined as the difference between $\mathrm{P}_{\mathrm{WF} \text { EMA }}$ and the standard deviation $\sigma$. Finally, the amount of fluctuating wind power required to be consumed by the hydrogen generator, $\mathrm{P}_{\text {HG_REF }}$, can be determined from the difference between $\mathrm{P}_{\mathrm{WF}}$ and $\mathrm{P}_{\mathrm{L} \_ \text {REF }}$, which is demonstrated in Fig.5. According to the normal distribution theory, it is expected that most of the output fluctuation of wind farm can be suppressed if the reference is calculated in this way.

\section{B) Centralized Control of Hydrogen Generator:}

Wind is intermittent and stochastic in nature and therefore, the wind farm output fluctuates randomly. To smooth this wind farm output by using multiple electrolyzer units a centralized control scheme is developed considering full load operation, switching reduction technique, and operational shifting of individual unit. The control block of the hydrogen generator is shown in Fig. 6. The input of the control block is the hydrogen generator reference power, $\mathrm{P}_{\text {HG_REF, }}$ which can be calculated using the procedure mentioned earlier. Based on this input total number of electrolyzer units required in 
smooth operation of wind farm output power will be determined. The comparator blocks help to ensure the full load operation. When some units are already in operation, another unit will only join with those units when additional fluctuating power is required to be absorbed, which helps to run the individual small unit close the rated condition most of the time. The output of the centralized control block is switching state signal, $\mathrm{E}(\mathrm{n})$, which is basically a ten element array with values 0 (off) or 1 (on). Multiple electrolyzer switching scheme explained in Sect. V.D determines E(n), considering operational shifting of different units. Switching reduction technique is implemented by using binary delay explained further in Sect. V.E.

\section{C) Control of Single Electrolyzer Unit Considering Soft Start Operation:}

A single electrolyzer unit shown by the dotted line in Fig. 5 is getting connected to the electrical supply by on/off control of the dc-chopper circuits using pulse width modulation (PWM) based duty cycle control scheme. The control block of the PWM switching of dc-chopper is shown in Fig. 7. In Fig. 7, the switching state signal, E(n), is obtained from centralized control block of hydrogen generator. The output of the control block is the IGBT switching signal, $\mathrm{S}_{\mathrm{n}}$, for individual electrolyzer unit of hydrogen generator. Total consumed power in HG system can be varied by switching on/off of individual unit maintaining the consumed power of each unit at rated level. Taking the advantage of PWM chopper duty cycle control, in this work, soft start operation of electrolyzer unit is adopted instead of instant switching. For that purpose, the electrolyzer reference current is increased gradually by using a rate limiter as shown in Fig. 7.

\section{D) Switching Strategy for Multiple Electrolyzer Units}

A simple but effective algorithm is developed for the switching operation among the electrolyzer units in HG. The switching of the electrolyzer units is developed based on how many electrolyzer units are required to be switched on (Total Electrolyzer Number, TELN) at any particular instant and how many electrolyzer units are already in on state (Active Electrolyzer Number, AELN) in that instant. TELN is determined from the fluctuating part of wind farm output power, $\mathrm{P}_{\text {HG_REF, }}$ which is obtained from reference generation scheme as explained earlier in Sect. V.A. For example, an additional unit will be added when $P_{\text {HG_REF }}$ exceeds the cumulative capacity electrolyzer units which are already in on state. The flowchart of the multiple electrolyzer switching strategy is shown in Fig. 8.

A shifting technique is very essential to incorporate in the switching scheme of different electrolyzer units to avoid an inclination of the operation time of individual unit. In this work, shifting operation is determined according to the FIFO (First-In-First-Out) algorithm, i.e., an electrolyzer unit started (on) first, stops (off) also first, and vice versa when one electrolyzer unit needs to be switched off (or on). This concept is adopted in the algorithm by counting electrolyzer loading. 
When one electrolyzer unit comes into operation, its loading is considered to 1 . Consequently, the rest of the active electrolyzer loading increases by 1 from its present loading, provided that the maximum electrolyzer loading (Max EL) must not exceed the number of electrolyzer units in the hydrogen generator. During the starting operation of a new electrolyzer unit, Last Active Electrolyzer (LAEL) Flag is maintained. In the next starting operation, the electrolyzer next to the LAEL will be switched ON. On the other hand, when any electrolyzer needs to be switched off, the electrolyzer loading of all active electrolyzer is checked. Then, the electrolyzer whose loading is maximum will be switched off. Therefore, the electrolyzer started its operation first will be switched off first considering its maximum loading. In this way, the operation time of all electrolyzer units in the HG can be balanced. An example case is demonstrated in Fig. 9(a) and Fig. 9(b) where 3 electrolyzer units switching and loading strategy based on the aforementioned algorithm are shown, schematically. These patterns will be changed accordingly when the number of electrolyzer units will be chosen more or less than 3 . The centralized control block of hydrogen generator shown in Fig. 6 determines the switching state signal, E(n), for individual electrolyzer unit according to the aforementioned switching scheme and thus E(n) participate to generate switching signal for particular electrolyzer through dc-chopper control block shown in Fig. 7.

\section{E) Reduction of Electrolyzer Switching}

It should be noted that any small fluctuation of wind farm output may cause to switch on another small electrolyzer unit, which is not desirable from the viewpoint of lifetime and efficiency of each unit. This random switching can be avoided by adopting standard binary delay in the input of hydrogen generator control block as shown in Fig. 6, while determining total number of required electrolyzer units. The binery delay block means that when the input increases, the output will increase after any specified time, provided the input is still high, which eventually reduces the random switching of electrolyzer units.

\section{Model System}

In this study, aggregated wind farm model is considered, where several WTGSs are lumped together to obtain a large WTGS. The reason is that the detailed switching models are used instead of the time average model for frequency converter of VSWT-PMSG and 10 electrolyzer units of HG in the simulation analyses, which makes the simulation considerably slow. The model system used in the simulation study is shown in Fig. 10, where hydrogen generator is connected to the wind farm connection point K. The parameters of the PMSG are shown in Table. II. The system base is 5MVA. 


\section{VII.Simulation Results}

Real wind speed data obtained in Hokkaido Island, JAPAN, is used in the simulation to verify the effectiveness of the proposed system which is shown in Fig. 11. Time step and simulation time have been chosen $0.00002 \mathrm{sec}$ and $600 \mathrm{sec}$ respectively. The simulations have been performed by using PSCAD/EMTDC [28].

The responses related to the maximum power extraction from wind are shown in Figs. 11-14. The responses of wind farm output power (i.e., real power output from the grid side inverter of VSWT-PMSG), and rotor speed of PMSG are shown in Figs. 12 and 13, respectively. The real power reference of PMSG side boost converter calculated using MPPT is shown in Fig. 14 as explained in Sect. II and III. The DC-link voltage of the frequency converter is shown in Fig. 15, which is maintained constant by the grid side inverter. The grid side inverter also controls the reactive power of the grid and hence the terminal voltage of wind farm (i.e., terminal voltage at the high voltage side of the transformer located after the grid side inverter) can be maintained constant at the desired level which, in general, is set by the transmission system operators (TSOs) once or few times in a day as can be seen from Fig. 16. In this study, the wind farm output fluctuation is minimized using variable number of electrolyzer units by absorbing the real power above the reference line power, as explained earlier. This means that the fluctuating part of the wind farm output is absorbed by the hydrogen generator multiple electrolyzer units through the proposed switching scheme in a controlled and efficient way. The responses of line power reference and wind farm line power are shown together in Fig. 17. As a smoothing index, the frequency spectrum of the wind farm line power is also shown in Fig. 18. From Figs. 17 and 18 the smoothening of wind farm output fluctuation is noticeable. It can be noticed from Fig. 17 that the hydrogen generator cannot participate in the line power smoothing operation when wind farm output is below the reference power. However, the smoothing performance can be improved further by incorporating a very small energy storage system along with hydrogen generator. As switching scheme for the multiple electrolyzer units is focused in this study, we have not considered the energy storage system. The responses of total consumed power by 10 electrolyzer units and total hydrogen gas generation from hydrogen generator are shown in Fig. 19 and Fig. 20 respectively. From Fig. 19, it can be understood clearly that the multiple electrolyzer units are participated in the smoothing operation when required based on the reference set point explained in Sect. V.A by abosorbing the fluctuating part of wind farm output power.

Finally, real power responses of 10 individual electrolyzer units are shown in Fig. 21. It can be seen that the electrolyzer unit which comes into operation first is switched off also earlier when a unit requires to shutdown. The operation shifting worked well throughout the run time according to the proposed switching scheme. It should be noted that electrolyzer 
switching for a very short period might not be logical from the practical point of view as electrolysis is a chemical process. This issue can be solved by adopting sophisticated control strategy considering the electrolyzer switching time. Incorporation of a small size energy storage system (ESS) might be a good solution to resolve the problem without degrading the smoothing performance of wind farm line power for that particular short period. Moreover, smoothing performance can be improved when wind farm output goes below the reference power, which is not possible by considering only hydrogen generator as discussed earlier. These issues would be reported in future work.

\section{Conclusions}

Though wind power is considered as a prospective energy source, wind power fluctuation due to randomly varying wind speed is still a serious problem for power grid companies or transmission system owners (TSO). On the other hand, hydrogen generation using wind energy is drawing much attraction these days. Considering these, in this paper, a cooperative control system is developed between variable speed wind farm composed of VSWT-PMSGs and hydrogen generator with multiple electrolyzer units, which can smoothen the line power and generate hydrogen gas without incorporating costly energy storage system (ESS). The multiple electrolyzer units help the hydrogen generator to avoid operation in partial loading condition which reduces the chance in degrading the electrolyzer performance. The novel switching strategy based on FIFO algorithm for the operation of multiple electrolyzer units help individual unit working in full load condition and hence increases their service life as well as improves the overall performance of the hydrogen generator. It is noted that the multiple electrolyzer switching scheme proposed in this paper can also be effective when hydrogen generator is connected to the DC-bus of the wind generator by improving the coordinated control scheme, which can also improve the overall efficiency of the system. Finally, it is concluded that the proposed cooperative control system can be applied to a wind farm successfully; obtaining increased overall performance from hydrogen generator and decreasing the cost of energy storage unit.

\section{References}

[1] Technical report from US Department of Energy, "Hydrogen Fuel Cell Engines, Module 1:Hydrogen Properties,” Revision 0, December 2001, [Online], http://www1.eere.energy.gov/hydrogenandfuelcells/tech_validation/pdfs/fcm01r0.pdf

[2] The Global Wind Energy Council, GWEC Latest News, 2008, "US, China \& Spain lead world wind power market in 2007," February, 2008, [Online], http://www.gwec.net/ 
[3] F. V. hulle, "Large Scale Integration of Wind Energy in the European Power Supply Analysis, Issue and Recommendations," EWEA, Tech. Rep., December 2005.

[4] N. A. Janssens, G. Lambin, and N. Bragard, “Active Power Control Strategies of DFIG Wind Turbines,” IEEE Power Tech, Paper No. 167, Switzerland, July 2007.

[5] E. Muljadi, C. P. Butterfield, B. Parsons, and A. Ellis, "Effect of Variable Speed Wind Turbine Generator on Stability of a Weak Grid,” IEEE Trans. on Energy Conversion, Vol.22, No.1, pp.29-36, 2007.

[6] P. Ledesma and J. Usaola, "Doubly fed induction generator model for transient stability analysis," IEEE Trans. on Energy Conversion, Vol.20, No.2, pp.388-397, 2005.

[7] P. La Seta and P. Schegner, "Comparison of stabilizing methods for doubly-fed induction generators for wind turbines," International Conference on Future Power System, Conference CDROM, 2005.

[8] T. Sun, Z. Chen, and F. Blaabjerg, "Transient stability of DFIG wind turbines at an external short-circuit fault," Wind Energy, Vol.8, No.3, pp.345-360, 2005.

[9] Peter Vas, "Electrical machines and Drives- A Space Vector Theory Approach," Oxford University Press, New York, United States, 1992.

[10] T. J. E. Miller, "Brushless Permanent-Magnet and Reluctance Motor Drives," Oxford University Press, New York, United States, 1989.

[11] N. A. Cutululis, E. Ceanga, A. D. Hansen, and P. Sørensen, "Robust multi-model control of an autonomous wind power system," Wind Energy, Vol.9, No.5, pp. 399-419, 2006.

[12] K. Tan and S. Islam, “Optimum Control Strategies in Energy Conversion of PMSG Wind Turbine System Without Mechanical Sensors,” IEEE Trans. on Energy Conversion, Vol.19, No.2, pp.392-399, 2004.

[13] M. Chinchilla, S. Arnaltes, and J. C. Busgos, "Control of Permanent-Magnet Synchronous Generators Applied to Variable-Speed Wind-Energy Systems Connected to the Grid," IEEE Trans. on Energy Conversion, Vol.21, No.1, March 2006.

[14] J. Zhang, M. Cheng, Z. Chen, "Nonlinear Control for Variable-speed Wind Turbines with Permanent Magnet Generators," Proceeding of International Conference on Electrical Machines and Systems (ICEMS 2007), pp-324-326, Seoul, Korea, Oct 2007.

[15] Z. Chen and E. Spooner, “Grid Power Quality with Variable Speed Wind Turbines,” IEEE Trans. on Energy Conversion, Vol. 16, No. 2, pp. 148-154, June 2001.

[16] S. Morimoto, T. Nakamura, and Y. Takeda, "Power Maximization Control of Variable-Speed Wind Generation System Using Permanent Magnet Synchronous Generator," IEEJ Trans. on P.E., Vol. 123-B, No.12, pp.1573-1579, 2003.

[17] S. M. Muyeen, R. Takahashi, T.Murata, J.Tamura, and M. H. Ali, "Transient Stability Analysis of Permanent Magnet Variable Speed Synchronous Wind Generator,” Proceedings of International Conference on Electrical Machines and Systems 2007 (ICEMS 2007), pp.288-293, Seoul, Korea, October 2007. 
[18] M.E. Haque, k.M. Muttaqi, and M. Negnevitsky, "Control of a stand alone variable speed wind turbine with a permanent magnet synchronous generator," IEEE Power and Energy Society General Meeting-Conversion and Delivery of Electrical Energy in the 21st Century, 2008.

[19] S. M. Muyeen, R. Takahashi, T. Murata, and J.Tamura, “A Variable Speed Wind Turbine Control Strategy to Meet Wind Farm Grid Code Requirements," Paper Accepted for Publication in IEEE Trans. on Power System.

[20] L.J. Fingersh, “Optimized Hydrogen and Electricity Generation from Wind,” National Renewable Energy Laboratory, NREL/TP500-34364, pp.1-12, June 2003.

[21] H. Nakabayashi, R. Takahashi, T. Morata, J. Tamura, M. futami, M. Ichinose, K. Ide, K. Fujii, and T. Itabashi, "Fundamental Research of Hydrogen Production System Using Variable Speed Wind Generator,” XVII International Conference on Electrical Machines (ICEMS06), Conf. CDROM Ref. No. 316, Greece, 2006.

[22] Rodolfo Dufo-Lopez, Jose L. Bernal-Agustin, Javier Contreras, "Optimization of control strategies for stand-alone renewable energy systems with hydrogen storage," Renewable Energy, Vol.32, No.7, pp.1102-1126, 2007.

[23] R. Kottenstette, J. Cotrell, "Hydrogen Storage in Wind Turbine Towers," National Renewable Energy Laboratory, NREL/TP-50034656, pp.1-21, September 2003.

[24] S. M. Muyeen, T. Murata, and J.Tamura, Stability Augmentation of a Grid-connected Wind Farm, Springer-Verlag London, ISBN 978-1-84800-315-6, October 2008.

[25] S. M. Muyeen, S. Shishido, Mohd. Hasan Ali, R. Takahashi, T. Murata, and J.Tamura, “Application of Energy Capacitor System (ECS) to Wind Power Generation," Wind Energy, Vol. 11, No. 4, pp. 335-350, DOI: 10.1002/we.265, July/August 2008.

[26] S. Heier, Grid Integration of Wind Energy Conversion System, Chicester, UK, John Wiley \& Sons Ltd., 1998.

[27] J. G. Slootweg, S. W. H. De Hann, H. Polinder, W. L. Kling, “General Model for Representing Variable Speed Wind Turbines in Power System Dynamic Simulations,” IEEE Trans. on Power System, Vol.18, No.1, 2003.

[28] PSCAD/EMTDC Manual, Manitoba HVDC Research Center, April 2005.

[29] A.M. Gole, I.T. Fernando, G.D. Irwin, andO.B. Nayak, "Modeling of power electronic apparatus: Additional interpolation issues" International Conference on Power Systems Transients (IPST), Seattle, Washington, June 1997.

[30] F. Barbir, "PEM electrolysis for production of hydrogen from renewable energy sources," Solar Energy, Vol.78, Issue.5, pp.661669, May 2005.

[31] R.E.Clarke, S.Giddey, F.T. Ciacchi, S.P.S.Badwal, B.Paul, J.Andrews, "Direct coupling of an electrolyser to a solar PV system for generating hydrogen,” International Journal of Hydrogen Energy, Vol.34, Issue.6, pp.2531-2542, March 2009.

[32] Richa Kothari, D. Buddhi, and R.L. Sawhney, "Studies on the effect of temperature of the electrolytes on the rate of production of hydrogen,” International Journal of Hydrogen Energy,Vol.30, Issue.3, pp.261-263, March 2005. 



\section{List of Tables and Figures:}

\section{Tables:}

Table I: Parameters of Single Electrolyzer Unit

Table II: Generator Parameters

\section{Figures:}

Fig. 1. Turbine characteristic with maximum power point tracking

Fig. 2. Electrical scheme-1 of VSWT-PMSG

Fig.3. Electrical scheme-2 of VSWT-PMSG

Fig. 4. Hydrogen generator with 10 electrolyzer unit

Fig. 5. Generation of hydrogen generator consumed power reference

Fig. 6. Hydrogen generator control block

Fig. 7. Control block for individual electrolyzer dc-chopper unit

Fig. 8. Electrolyzer switching strategy

Fig. 9(a). 3 electrolyzer units switching operation

Fig. 9(b). 3 electrolyzer units loading operation

Fig. 10. Model system

Fig. 11. Wind speed data

Fig. 12. Wind farm output power

Fig. 13. Rotor speed of PMSG

Fig. 14. Power reference of PMSG side converter using MPPT

Fig. 15. DC-link voltage of the frequency converter of VSWT-PMSG

Fig. 16. Terminal voltage of wind farm

Fig. 17. Line power of wind farm

Fig. 18. Frequency spectrum of line power

Fig. 19.Hydrogen generator total consumed power

Fig. 20. Toral generated hydrogen gas

Fig. 21. Real powers of 10 individual electrolyzer units. 
TABLE I

PARAMETER OF SINGLE ELECTROLYZER UNIT

\begin{tabular}{|l|l|}
\hline Rated capacity of one block & $0.18[\mathrm{MW}]$ \\
\hline Rated voltage $\mathrm{V}_{\mathrm{H}}$ & $0.43 \mathrm{k}[\mathrm{V}]$ \\
\hline Internal resistance $\mathrm{R}_{\mathrm{H}}$ & $0.124[\Omega]$ \\
\hline Internal voltage $\mathrm{E}_{\mathrm{H}}$ & $0.379[\mathrm{kV}]$ \\
\hline Reactor $\mathrm{L}_{\mathrm{H}}$ & $1.0[\mathrm{mH}]$ \\
\hline Capacitor $\mathrm{C}_{\mathrm{H}}$ & $200[\mu \mathrm{F}]$ \\
\hline Reactor $\mathrm{L}_{\mathrm{r}}$ & $0.5[\mathrm{mH}]$ \\
\hline Capacitor $\mathrm{C}_{\mathrm{r}}$ & $3.0[\mu \mathrm{F}]$ \\
\hline
\end{tabular}

TABLE II

GENERATOR PARAMETERS

\begin{tabular}{|c|l|l|l|}
\hline Rated Power & $5[\mathrm{MW}]$ & Stator Resistance & $0.01[\mathrm{pu}]$ \\
\hline Roltage & $1.0[\mathrm{kV}]$ & d-axis Reactance & $1.0[\mathrm{pu}]$ \\
\hline Frequency & $20[\mathrm{~Hz}]$ & q-axis Reactance & $0.7[\mathrm{pu}]$ \\
\hline Number of Poles & 150 & Field Flux & $1.55[\mathrm{pu}]$ \\
\hline $\mathrm{H}$ & $3.0[\mathrm{sec}]$ & & \\
\hline
\end{tabular}




\section{Figures:}

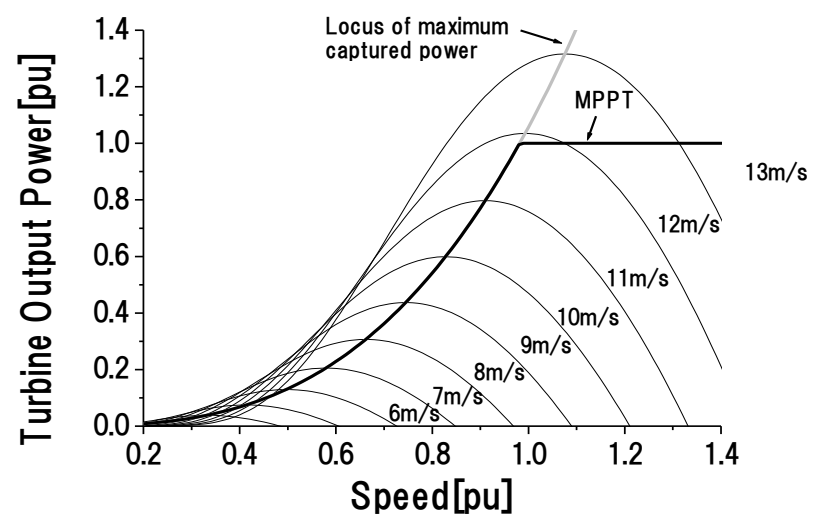

Fig. 1. Turbine characteristic with maximum power point tracking

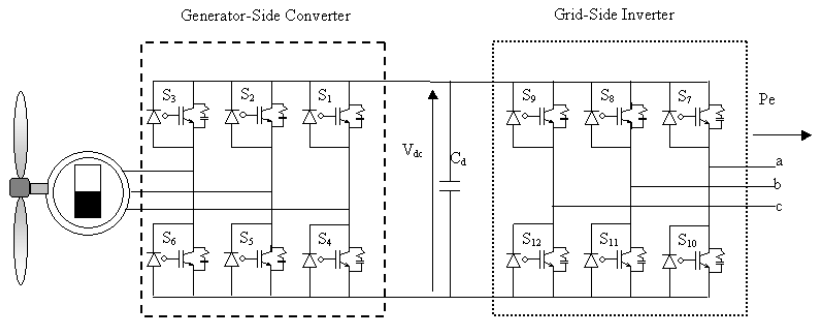

Fig. 2. Electrical scheme-1 of VSWT-PMSG

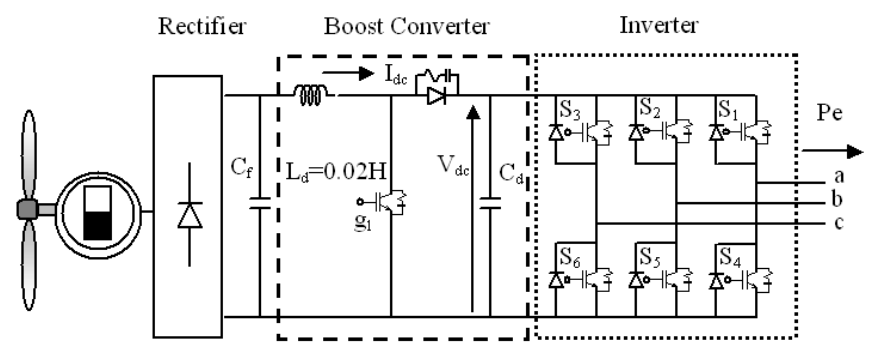

Fig.3. Electrical scheme-2 of VSWT-PMSG 


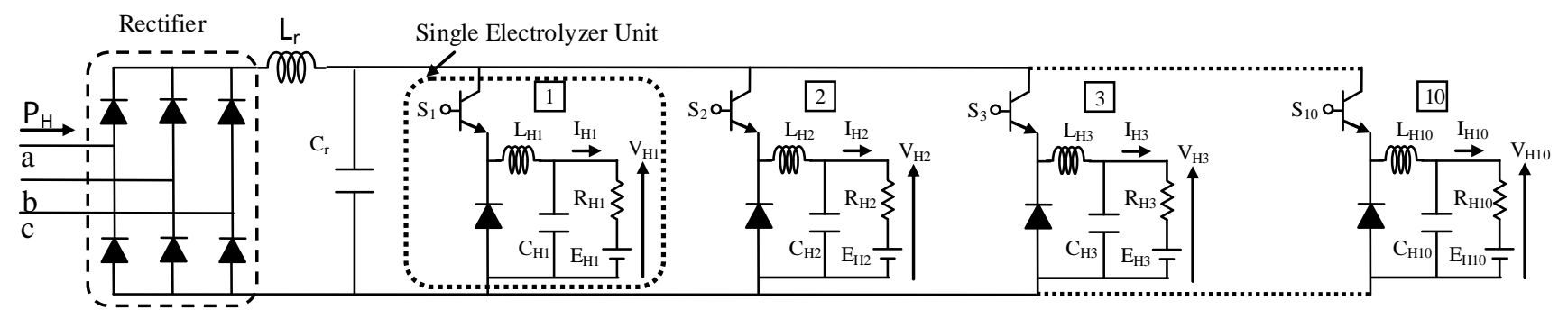

Fig. 4. Hydrogen generator with 10 electrolyzer unit

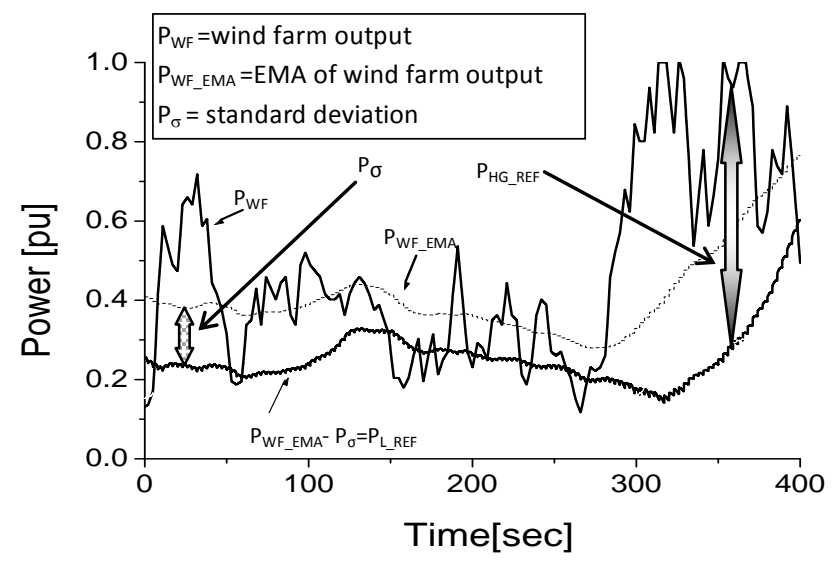

Fig. 5. Generation of hydrogen generator consumed power reference

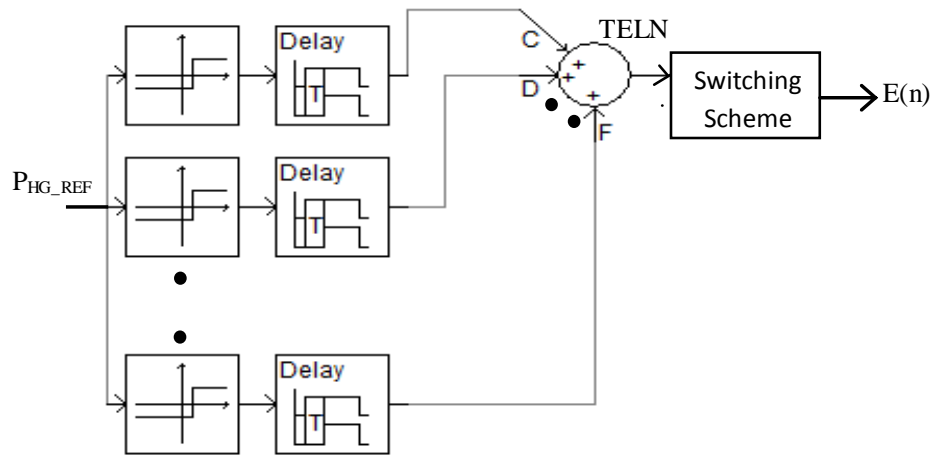

Fig.6. Hydrogen generator control block 


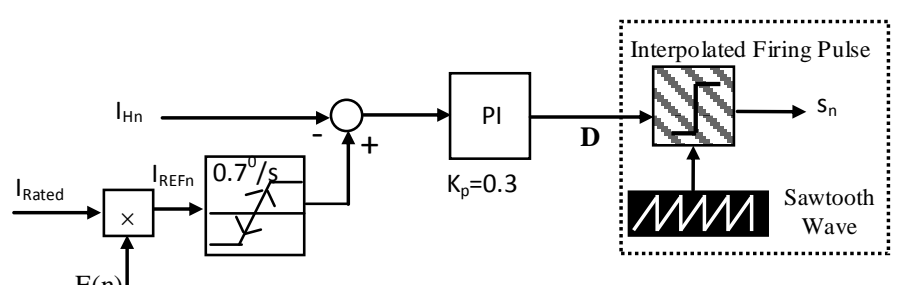

Fig.7. Control block for individual electrolyzer dc-chopper unit

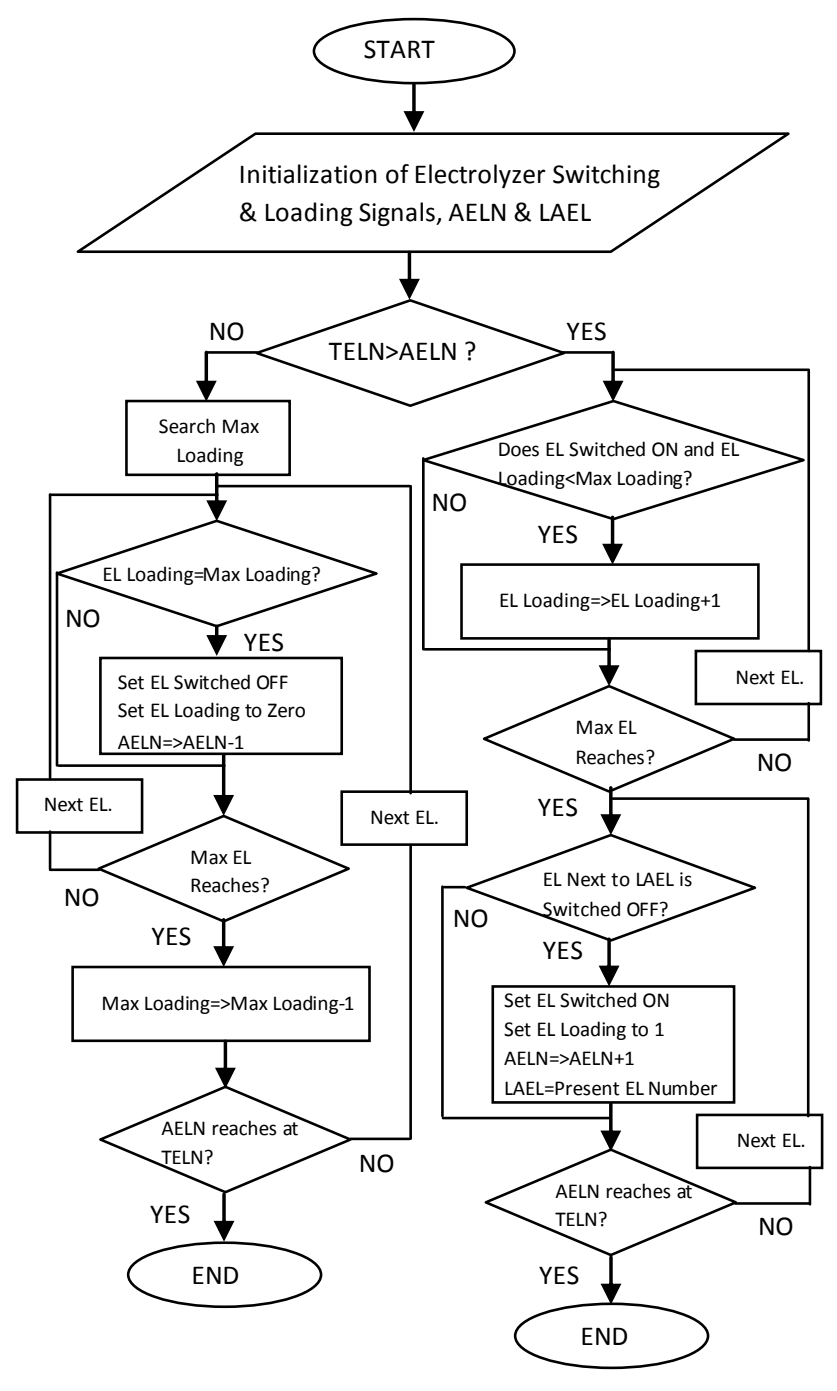

Fig. 8. Multiple Electrolyzer switching strategy 

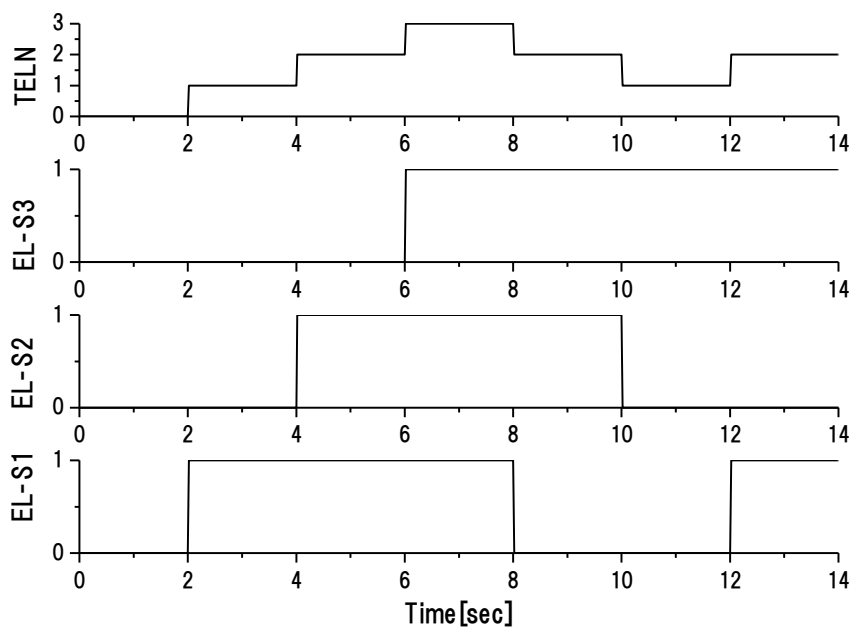

Fig. 9(a). 3 electrolyzer units switching operation

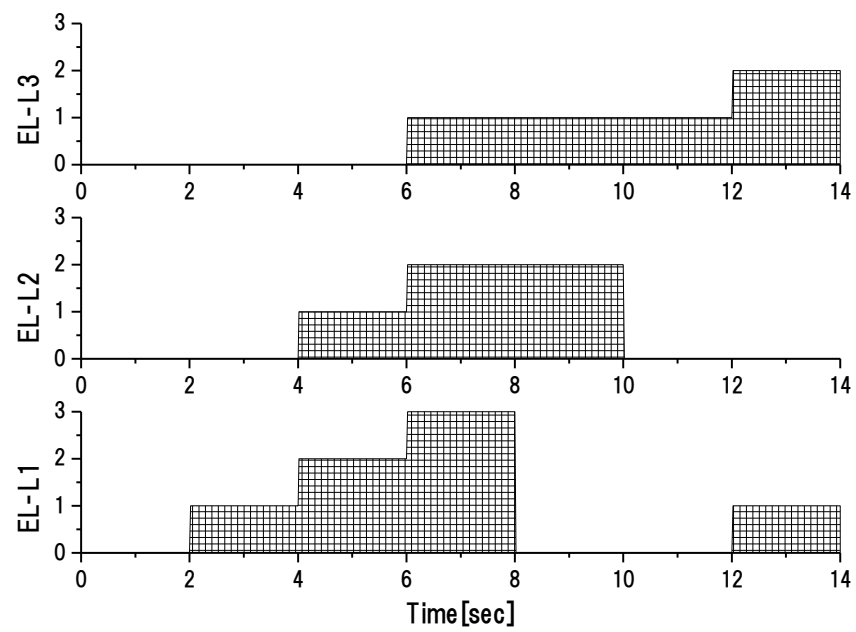

Fig. 9(b). 3 electrolyzer units loading operation 


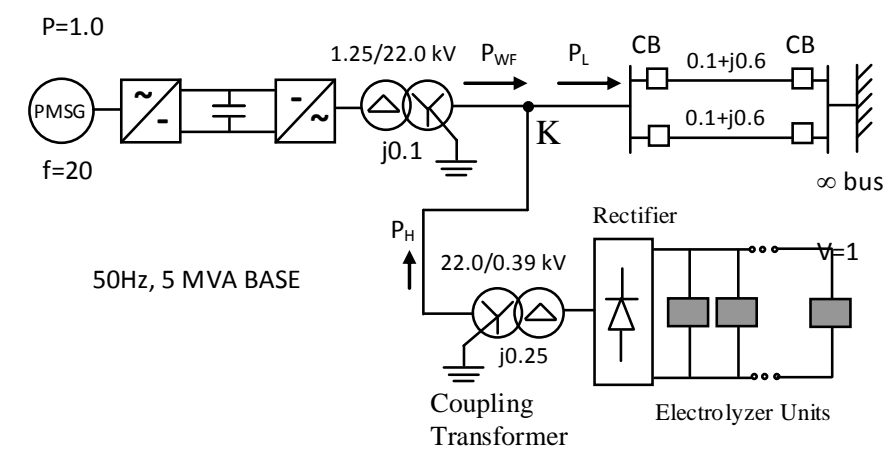

Fig. 10 Model System

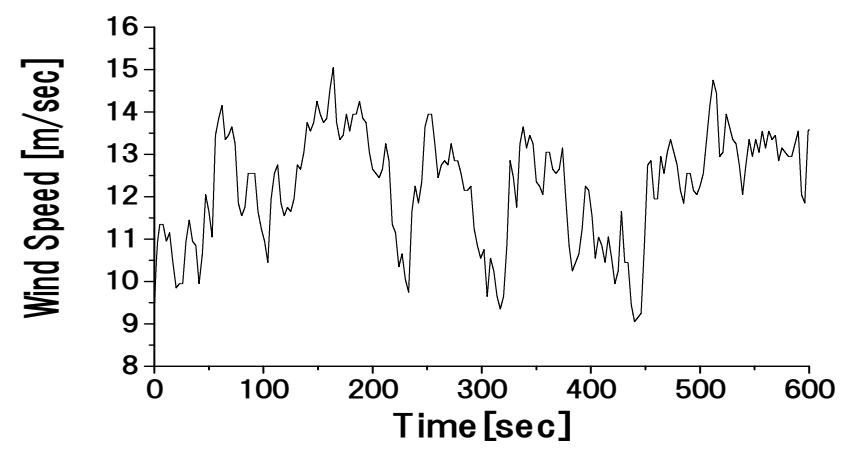

Fig. 11. Wind speed data

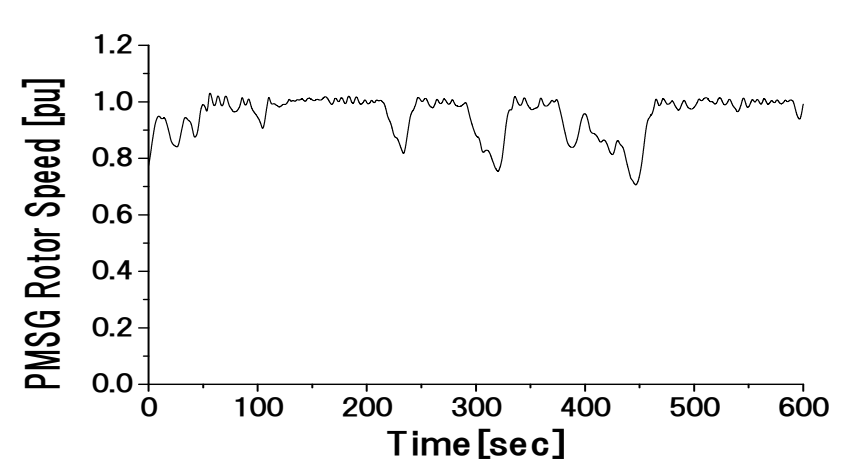

Fig. 13. Rotor speed of PMSG

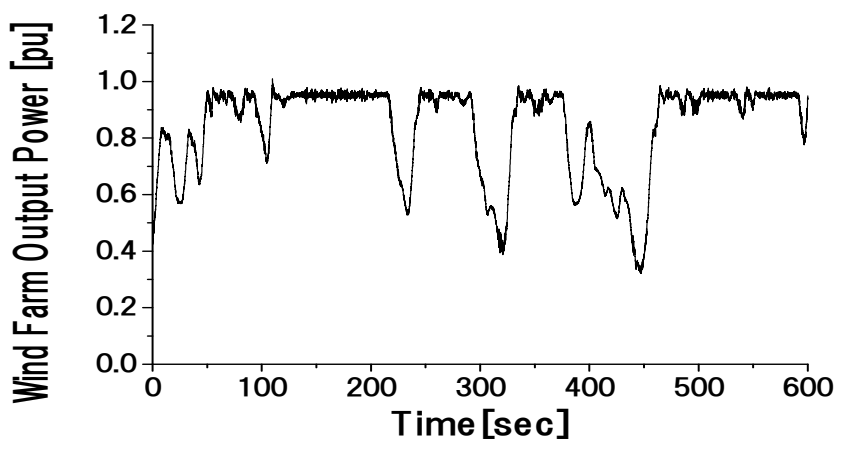

Fig. 12. Wind farm output power

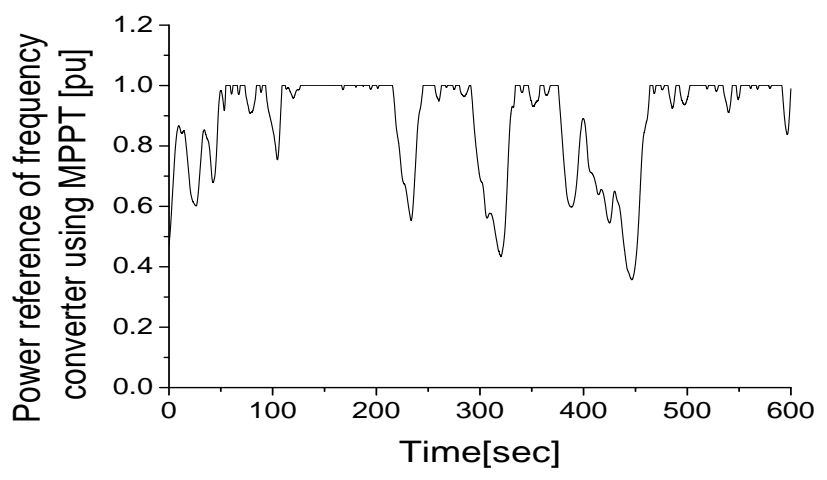

Fig. 14. Power reference of PMSG side converter using MPPT 


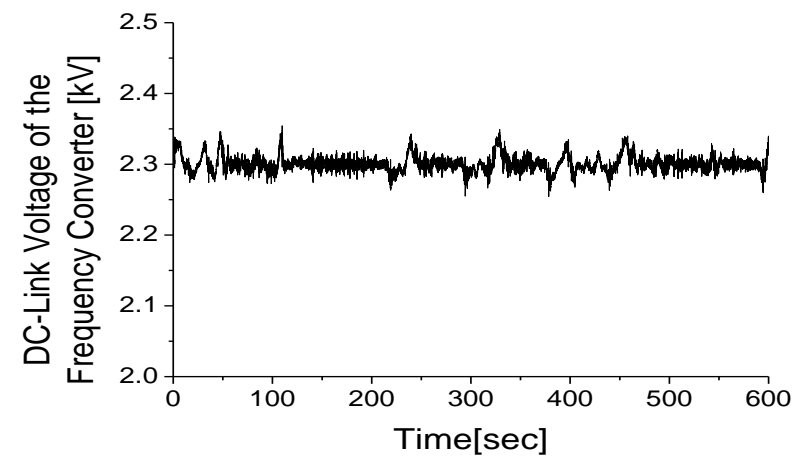

Fig. 15. DC-link voltage of the frequency converter of VSWT-PMSG

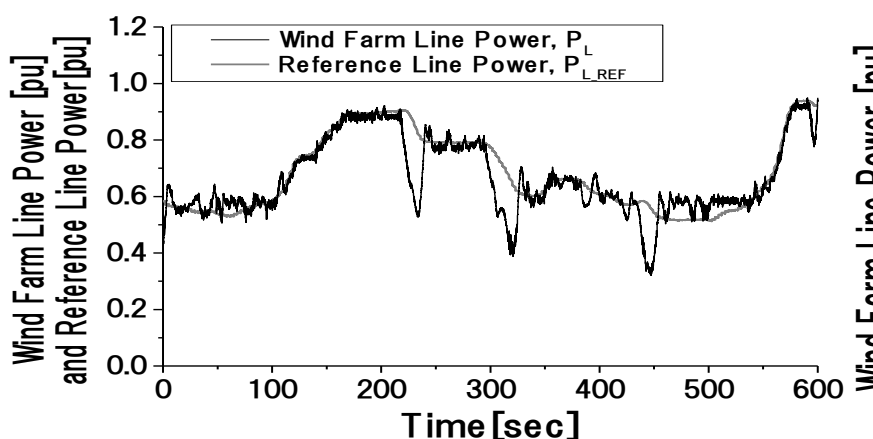

Fig. 17. Line power of wind farm

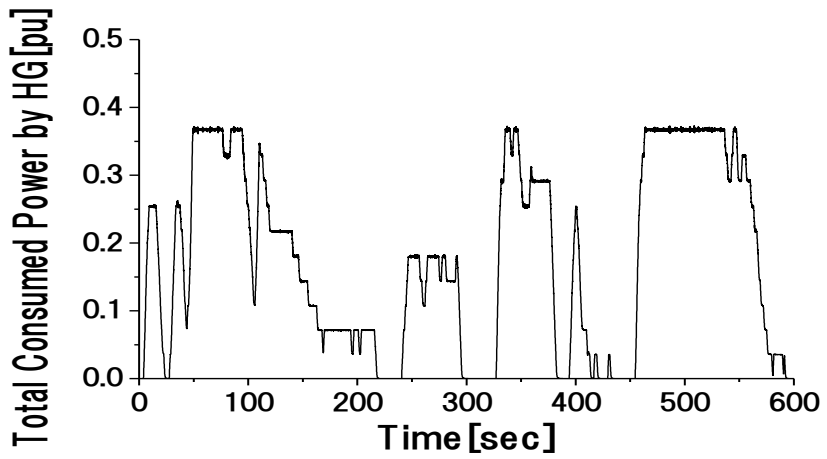

Fig. 19. Hydrogen generator total consumed power

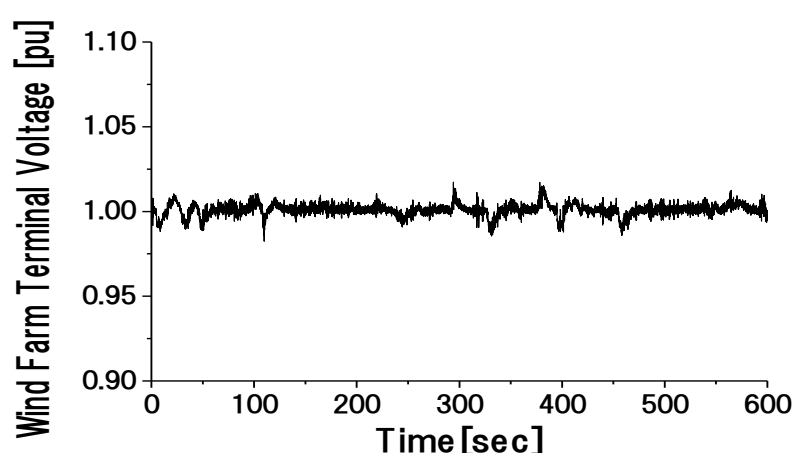

Fig. 16. Terminal voltage of wind farm

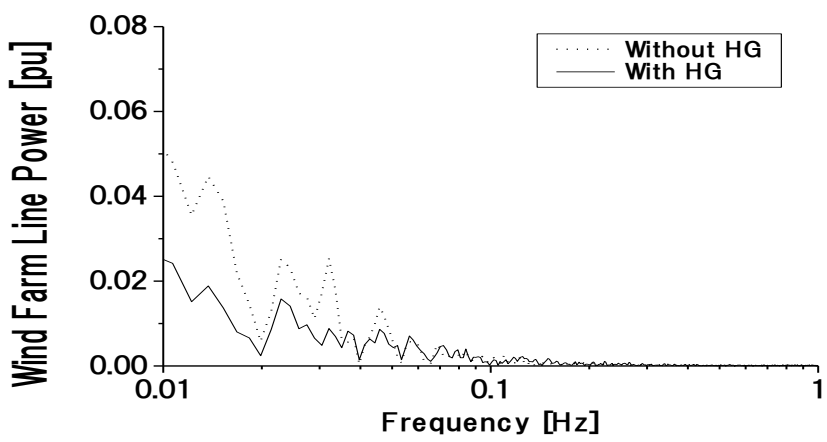

Fig. 18. Frequency spectrum of line power

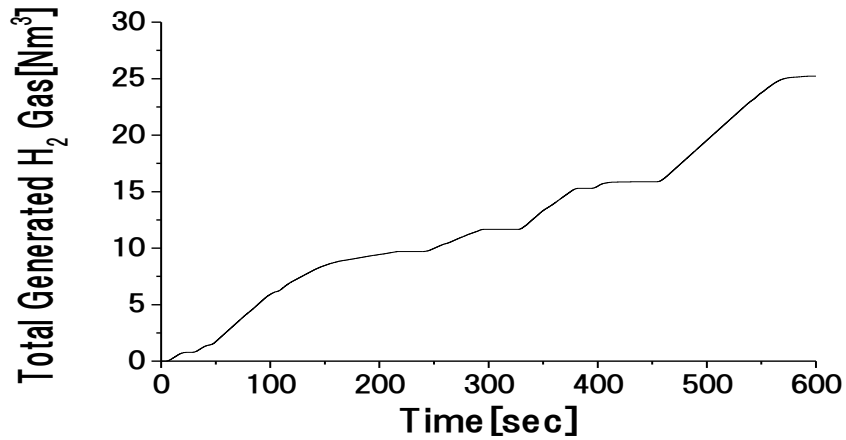

Fig. 20. Total generated hydrogen gas 

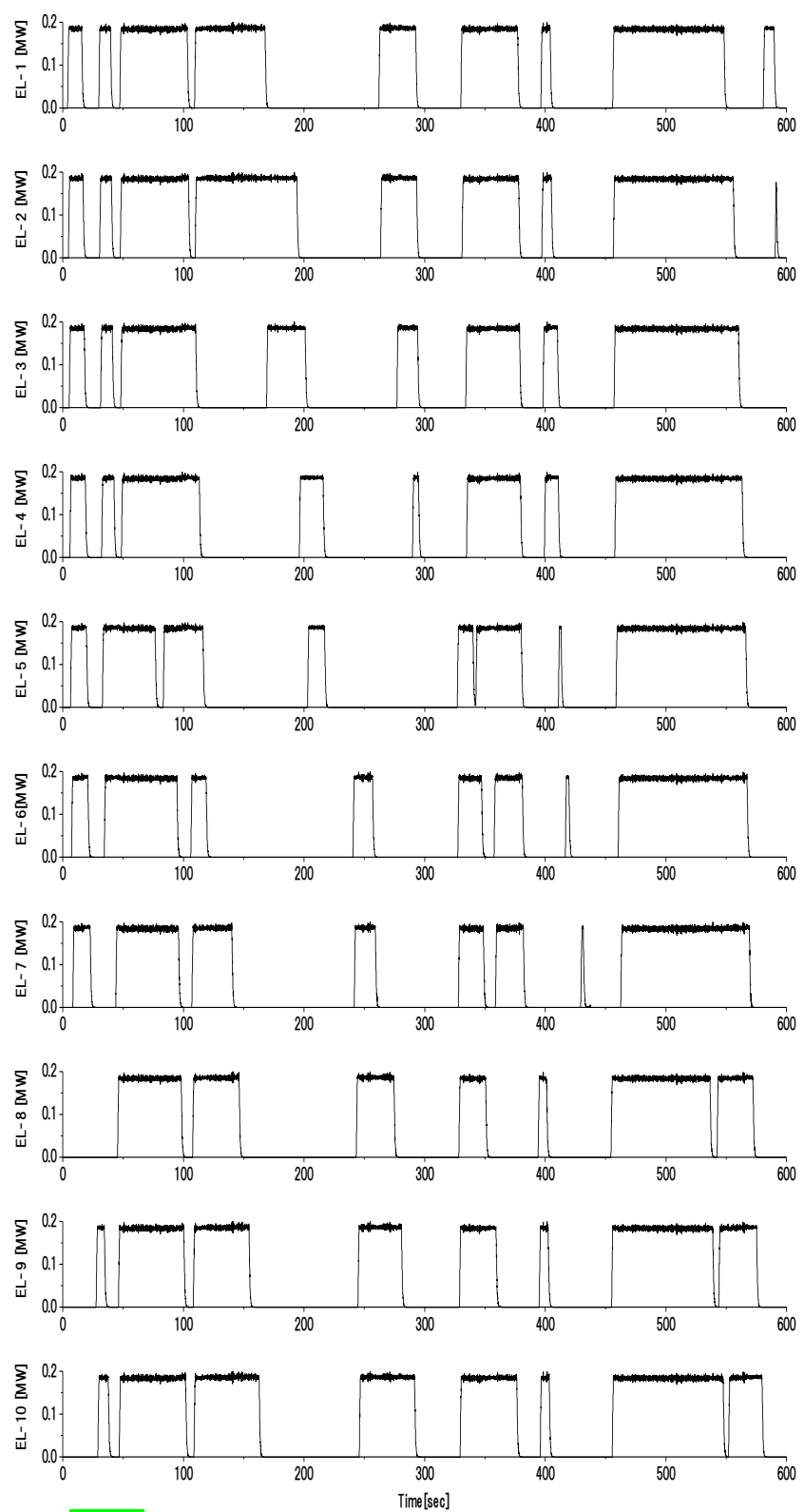

Fig. 21. Real powers of 10 individual electrolyzer units 